\title{
PERANCANGAN APLIKASI MOBILE APPS UNTUK PENGOLAHAN KEY PERFORMANCE INDICATOR KARYAWAN PADA PT. SOLUTECH GLOBAL
}

\author{
Reni Febrianti ${ }^{1}$ \\ ${ }^{1}$ Program Studi Akuntansi \\ Universitas Mohammad Husni Thamrin \\ nibhot@gmail.com
}

\author{
Akbar As Syidiqi ${ }^{2}$ \\ ${ }^{2}$ Program Studi Teknik Informatika \\ Universitas Mohammad Husni Thamrin \\ akbarsyidiq@gmail.com
}

\begin{abstract}
Data processing key performance indicators on old systems has many shortcomings, especially in terms of energy efficiency, time, and data storage security. The purpose of this design is to overcome the above problems. The method used in this design is rapid application development. Data collection tools and materials in this design are observation and reference books.

The findings from the results of data analysis show that this mobile application can process key performance indicator data more easily and efficiently. The conclusion from this design is that this mobile apps application can increase the efficiency of key performance indicator data processing.
\end{abstract}

Keywords: applications, mobile apps, key performance indicators, data processing, efficiency

\begin{abstract}
Abstraksi- Pengolahan data key performance indicator pada sistem lama memiliki banyak kekurangan terutama dalam hal efisiensi tenaga, waktu, dan keamanan penyimpanan data. Tujuan dibuatnya perancangan ini adalah untuk mengatasi persoalan diatas. Metode yang digunakan dalam perancangan ini adalah rapid application development. Alat pengumpulan data dan materi dalam perancangan ini adalah observasi dan buku-buku referensi.

Temuan dari hasil analisis data menunjukan bahwa aplikasi mobile apps ini dapat mengolah data key performance indicator dengan lebih mudah dan efisien. Kesimpulan dari perancangan ini adalah aplikasi mobile apps ini dapat meningkatkan efisiensi pengolahan data key performance indicator.
\end{abstract}

Kata Kunci : aplikasi, mobile apps, key performance indicator, pengolahan data, efisiensi

\section{PENDAHULUAN}

Pada saat ini, sistem pengolahan data dengan menggunakan metode pembukuan sudah dinilai tidak efektif. Ini dikarenakan banyaknya perhitungan kompleks yang apabila dilakukan secara manual maka rentan terjadi human error. Hal ini berakibat fatal pada kesalahan pengolahan data yang akan merugikan perusahaan. Dari segi keamanan data pun termasuk minim. Buku atau catatan bersifat mudah rusak dan terbakar. Oleh karena itu, saat ini diperlukan cara alternatif untuk mengolah data.

Perkembangan teknologi informasi saat ini sudah semakin maju. Di era globalisasi saat ini, masyarakat di seluruh dunia semakin sering bertukar informasi. Baik secara individu maupun kelompok. Perusahaan di seluruh dunia juga kerap melakukan pemindahan data dari suatu tempat ke tempat yang lain. Para penggiat bisnis juga makin memperluas jangkauan koneksi dan ekspansi bisnisnya ke negara-negara lain. Hal ini terjadi karena dengan berkembangnya teknologi informasi saat ini, informasi semakin mudah didapatkan dan disebarluaskan.

Para pengembang perangkat lunak juga semakin inovatif dalam mengembangkan produknya. Hal ini berimbas pada berkembangnya aplikasi-aplikasi yang tersebar di masyarakat. Aplikasi tersebut turut mempermudah pengguna dalam menjalankan tugasnya. Aplikasi tersebut ada yang memiliki nilai jual, ada pula yang didapatkan secara gratis. 
PT. Solutech Global adalah perusahaan yang bergerak di bidang teknologi informasi. Untuk membuat suatu produk, perusahaan mencatat key performance indicator dalam bentuk pembukuan. Oleh karena itu, penggunaan aplikasi untuk mengolah data key performance indicator sangat dibutuhkan. PT. Solutech Global mencatat semua proses pengembangan perangkat lunak. Setiap fase pengembangan perangkat lunak tersebut terdapat key performance indicator untuk para analis dan programmer.

Analis akan membuat key performance indicator dan setiap programmer akan mendapat tugas untuk menyelesaikan key performance indicator tersebut berdasarkan divisi. Key performance indicator tersebut masing-masing memiliki durasi pengerjaan yang akan dihitung dan dicatat tiap minggunya. Hal ini membuat sistem perhitungan data key performance indicator yang diselesaikan programmer menjadi cukup rumit dan sulit dilakukan pendataan secara manual. Oleh karena itu, PT. Solutech Global membutuhkan suatu aplikasi yang dapat mengolah data key performance indicator.

\section{METODE PENELITIAN}

Key performance indicator merupakan indikator yang menunjukan apa yang perlu dicapai dalam pandangan internal operasional perusahaan untuk meningkatkan kinerja perusahaan. Key performance indicator fokus sebagai bagian dari suatu ukuran perusahaan atau organisasi yang merupakan hal yang penting untuk menuju sukses baik itu untuk sekarang atau masa depan.

Key performance indicator atau disingkat KPI adalah indikator kunci kinerja yang digunakan pada PT.
Solutech Global sebagai kunci untuk menilai kinerja para programmer dan analis dalam mengerjakan tugas yang diberikan oleh perusahaan. Setiap key performance indicator memiliki estimasi waktu pengerjaan dan tenggat waktu yang ditetapkan. Contoh key performance indicator misalnya membuat database, membuat template, merubah tampilan data, dan sebagainya. Perusahaan menetapkan key performance indicator yang yang harus dicapai programmer setiap minggu adalah 40 jam dan analis memiliki target 80 jam.

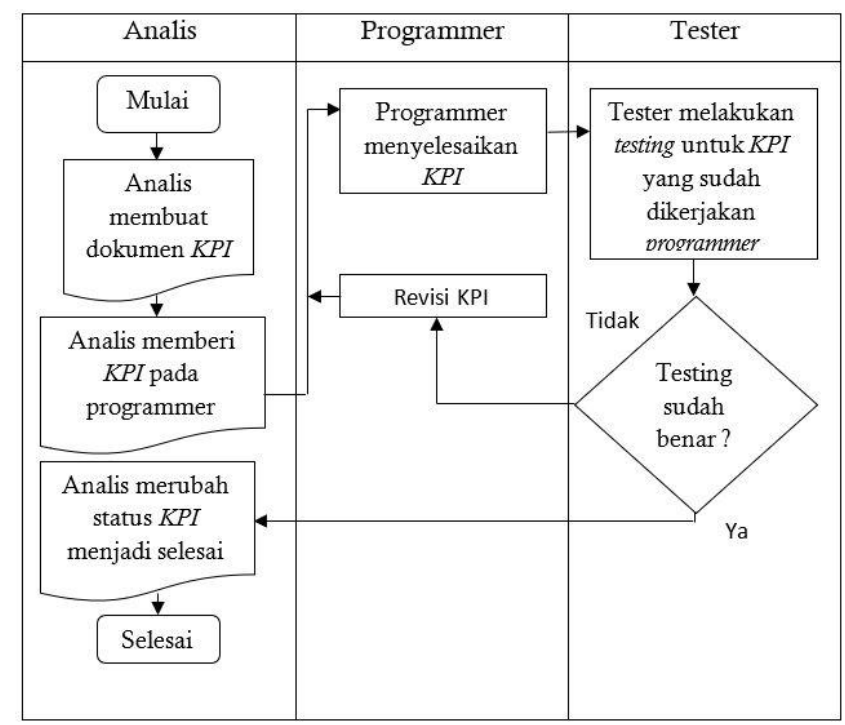

\section{Gambar 1. FOD Sistem Berjalan Key Performance Indicator}

Sistem usulan yang dirancang untuk PT. Solutech Global merupakan pengembangan dari sistem yang sudah berjalan dalam perusahaan. Tujuan dirancangnya sistem ini adalah untuk mengatasi masalah yang dialami perusahaan saat mengolah key performance indicator karyawan seperti penyimpanan data dalam bentuk kertas yang rawan rusak, sulit mengawasi pekerjaan programmer sehingga 
pengolahan data menjadi kurang efektif dan efisien. Sistem usulan tersebut adalah aplikasi mobile apps untuk pengolahan key performance indicator karyawan.

KPI merupakan tugas-tugas kerja yang dibuat oleh analis untuk dikerjakan programmer dalam membangun web atau aplikasi mobile, dan KPI tersebut akan diakumulasikan tiap minggu untuk melihat grafik KPI analis dan programmer sebagai alat bantu untuk menilai kinerja karyawan.

Pada aplikasi pengolahan data KPI karyawan terdapat 5 status yang dimiliki KPI dalam proses pembuatan hingga selesai, yaitu no-assignment (KPI yang belum diambil oleh programmer), on-progress (KPI yang telah diambil oleh programmer dan sedang dikerjakan), on-waiting (KPI yang sudah diselesaikan oleh programmer namun belum di tes), finetuning (KPI yang dikembalikan oleh analis ke programmer karena hasil tes menunjukan error sehingga harus diperbaiki), dan finish (KPI yang sudah di tes dan dianggap selesai oleh analis). Untuk lebih jelasnya, penjabaran alur yang terdapat pada aplikasi pengolahan KPI karyawan pada flowchart di bawah ini:

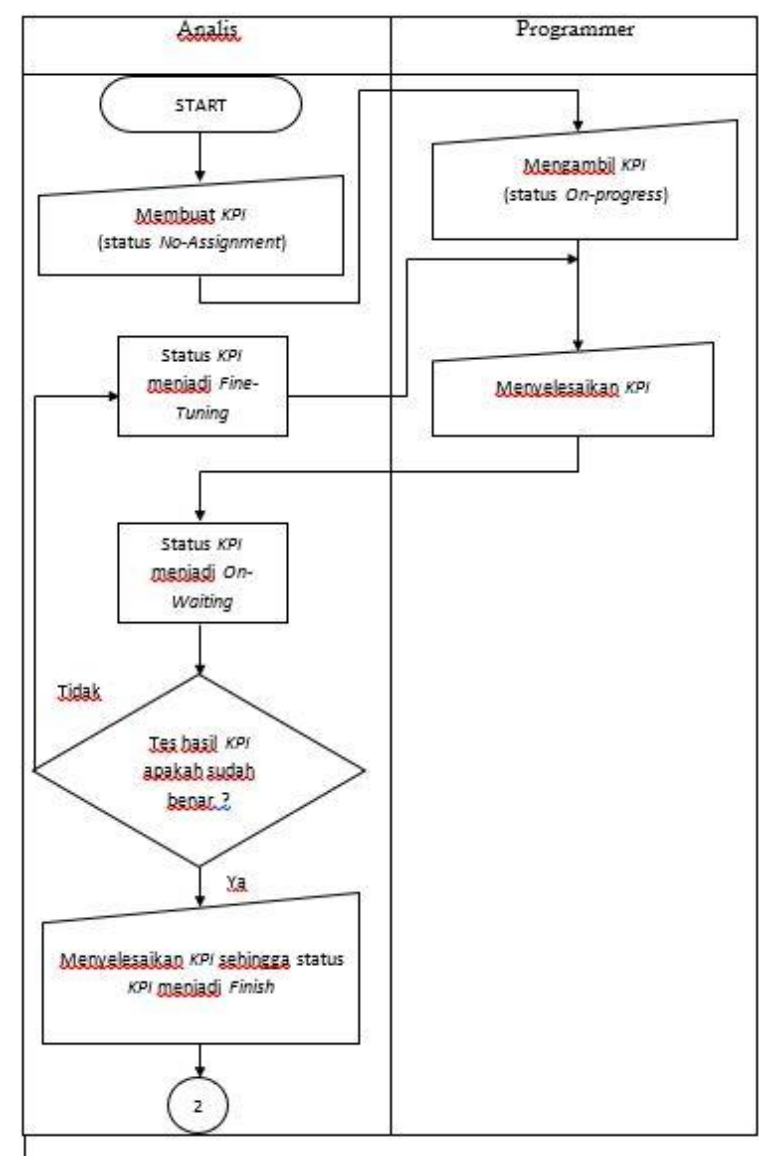

Gambar 2. Alur Usulan Pembuatan Key Performance Indicator

Keterangan :

1. Pertama, analis membuat KPI tanpa menunjuk programmer secara langsung (status NoAssignment).

2. Programmer mengambil KPI dengan status NoAssignment, lalu mengerjakan tugas sesuai dengan keinginan analis yang tercantum pada data KPI (status On-Progress).

3. Programmer selesai mengerjakan KPI (status OnWaiting).

4. Analis memeriksa KPI yang telah dikerjakan programmer. Jika hasil tes KPI sudah benar maka analis akan merubah status KPI menjadi Finish. 
Namun jika hasil tes menunjukan kesalahan atau error, maka status KPI akan berubah menjadi finetuning lalu KPI akan dikembalikan kepada programmer untuk memperbaiki error .

5. KPI yang berada dalam status Fine-Tuning akan terus diperbaiki oleh programmer hingga analis menyatakan hasil tes KPI sudah benar dan dinyatakan selesai.

6. Perhitungan kinerja berdasarkan jumlah jam KPI yang sudah diselesaikan antara hari Senin pukul 00:00 hingga hari Minggu pukul 23:59 di tiap pekan yang berlangsung. Penilaian kinerja karyawan dihitung berdasarkan pencapaian total jam KPI yang dimiliki oleh masing-masing analis dan programmer.

\section{HASIL DAN PEMBAHASAN}

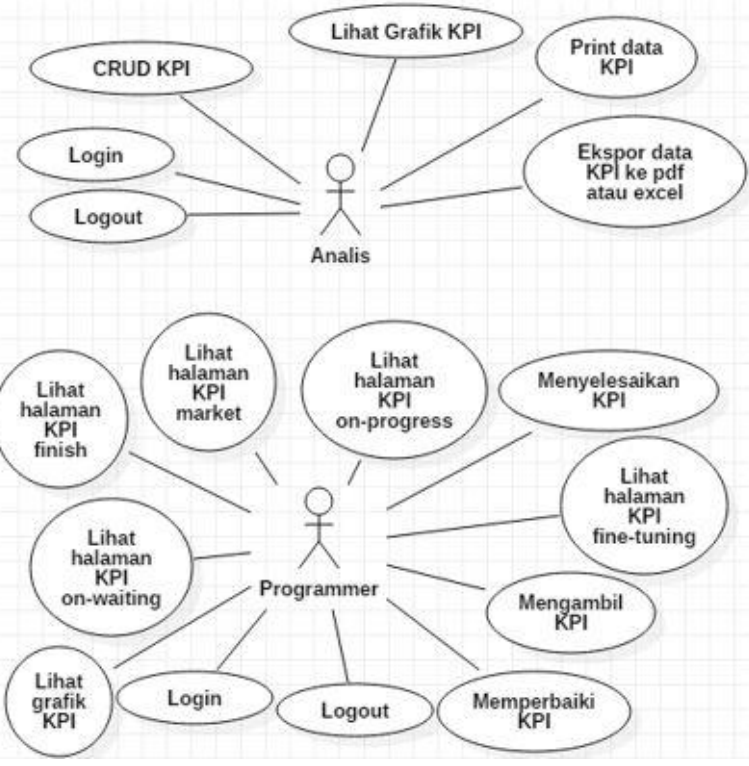

Gambar 3. Use case diagram 


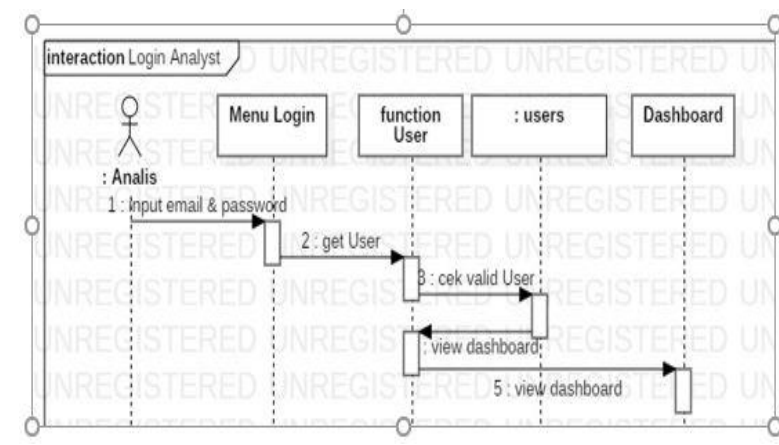

Gambar 5. Sequence diagram Login Analyst

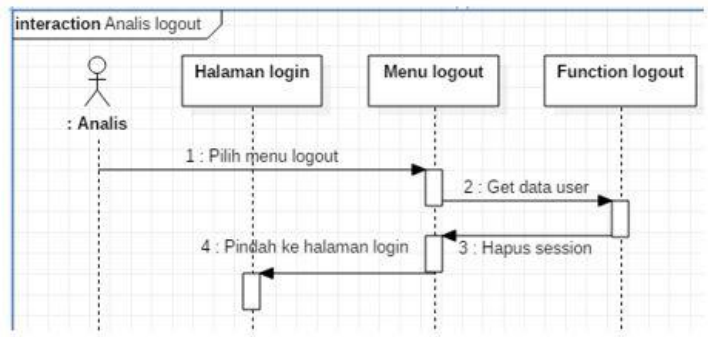

Gambar 6. Sequence diagram Logout Analyst

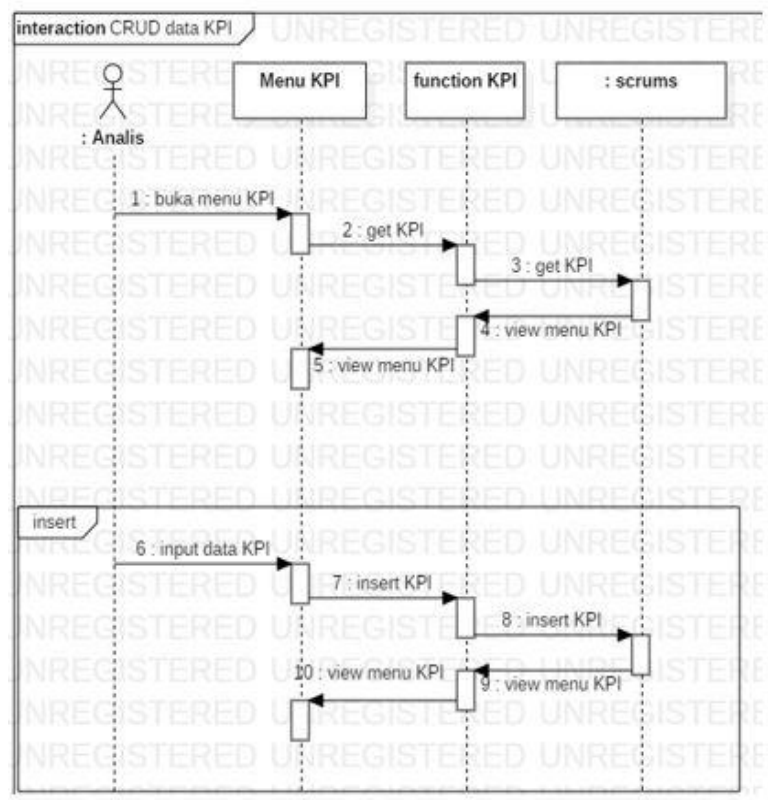

Gambar 7. CRUD data KPI Analyst Insert

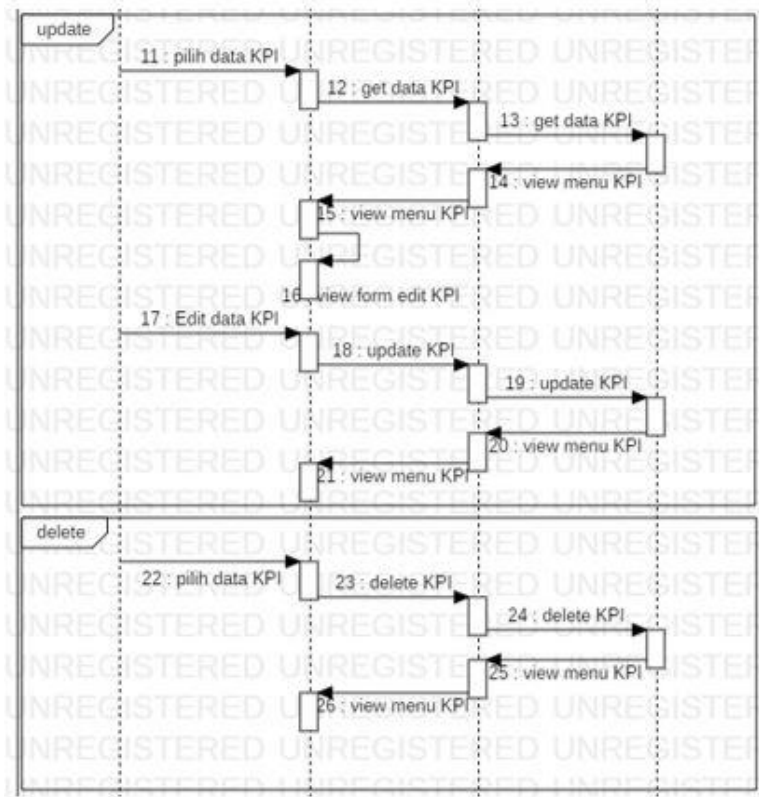

Gambar 8. CRUD data KPI Analyst Update dan Delete

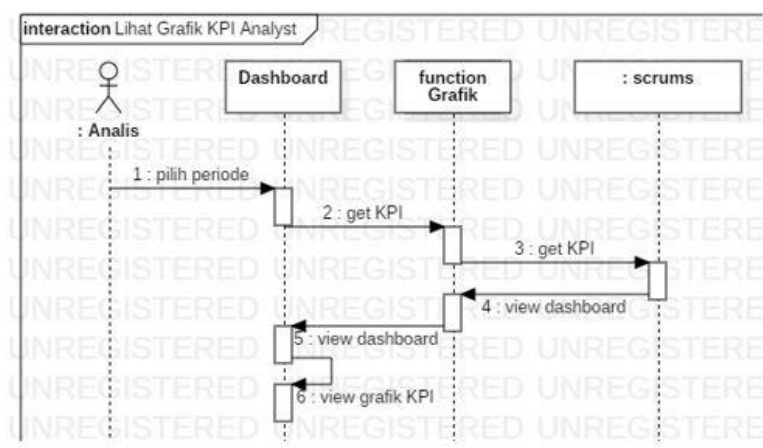

Gambar 9. Sequence lihat grafik KPI analyst 


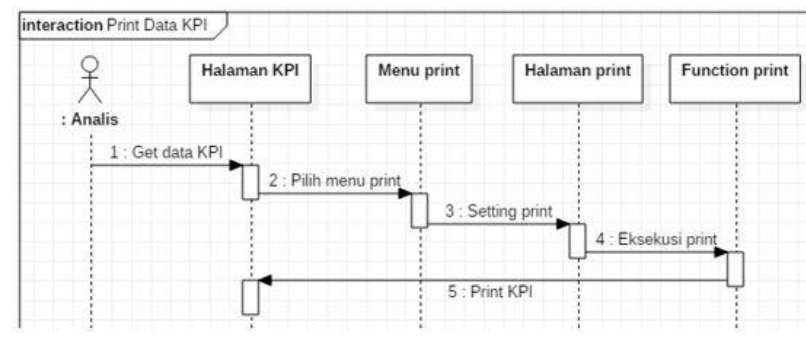

Gambar 10. Sequence print data KPI

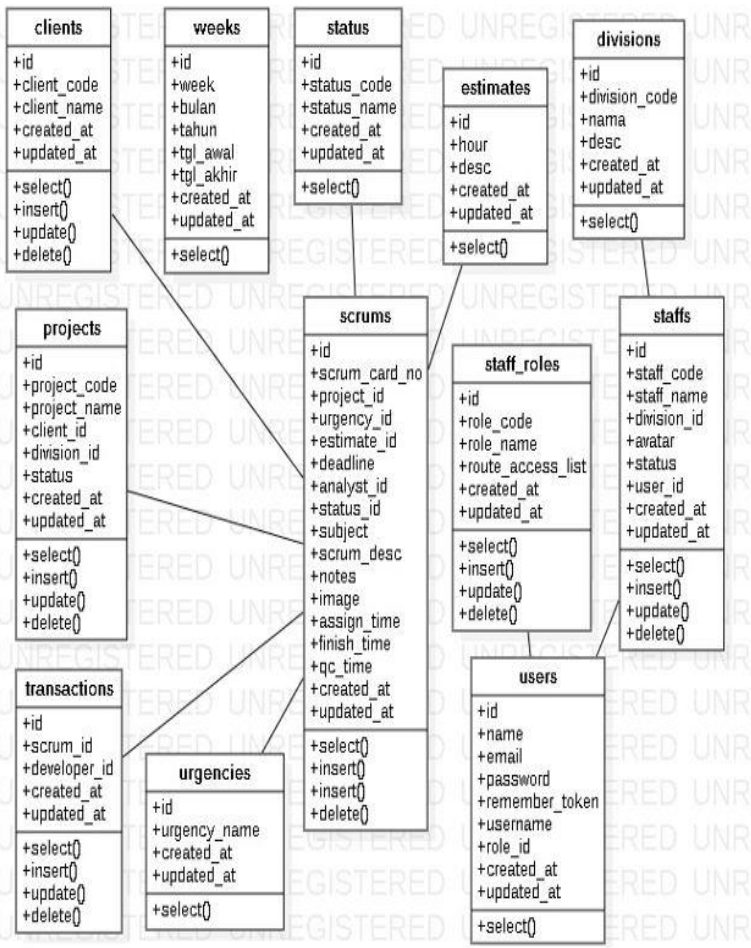

Gambar 11. Class Diagram

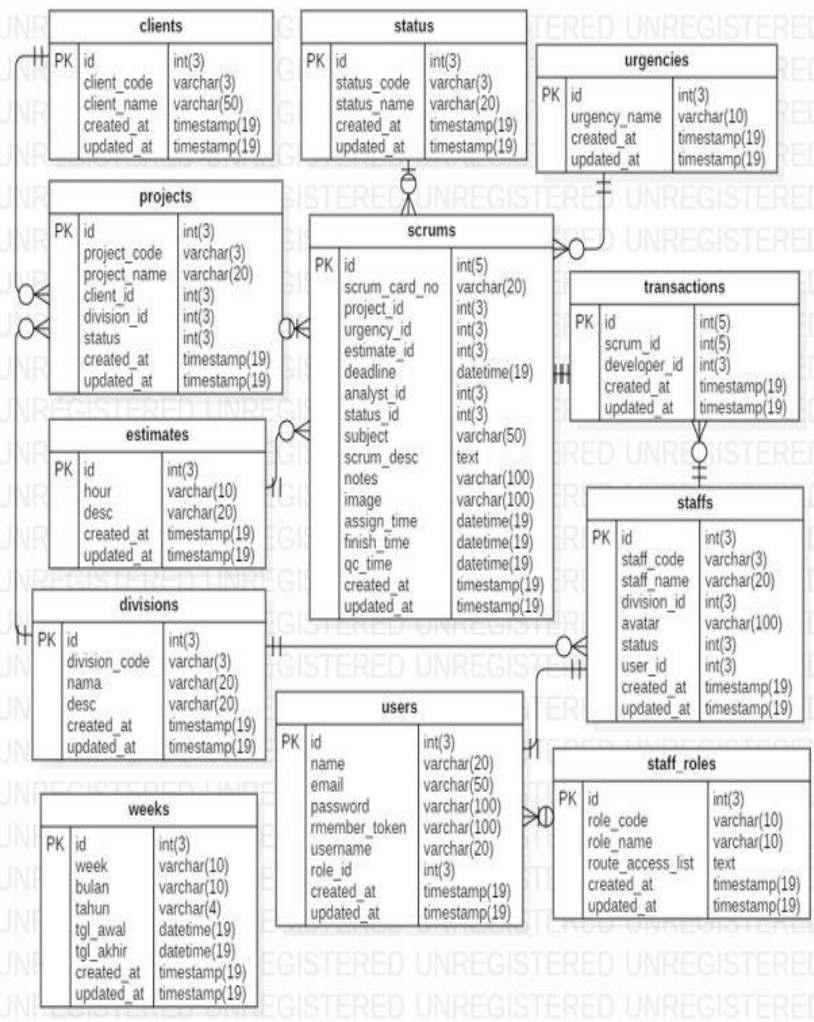

Gambar 12. Entity Relationship Diagram

\section{KESIMPULAN DAN REKOMENDASI}

Aplikasi pengolahan key performance indicator karyawan mampu mengatasi masalah yang dialami oleh PT. Solutech Global karena aplikasi ini memiliki banyak keunggulan dibanding sistem lama, dan dapat digunakan dimanapun dengan perangkat mobile. Sehingga pengolahan data dapat dilakukan secara lebih efektif dan efisien. Aplikasi ini merupakan modifikasi dari sistem lama sehingga pengguna dapat memahami aplikasi ini dengan lebih mudah.

Keunggulan yang dimiliki oleh aplikasi mobile apps pengolahan key performance indicator karyawan mampu menyimpan data secara digital sehingga lebih aman dan mudah di-backup, menyediakan informasi secara cepat dan akurat serta dapat melakukan 
perhitungan yang akurat saat akumulasi KPI sebagai tolak ukur kinerja para karyawan. Aplikasi ini mampu mengatasi permasalahan yang dialami oleh PT. Solutech Global dalam mengolah KPI.

Adapun rekomendasi yang dapat diberikan diantaranya:

Sistem pengolahan data KPI karyawan yang lama sudah memiliki alur pengolahan data yang tepat dan sesuai kebutuhan perusahaan, namun untuk mempermudah dan mempercepat pekerjaan dibutuhkan suatu aplikasi yang mampu mengolah KPI secara cepat dan akurat sehingga karyawan serta perusahaan dapat merasakan manfaat yang nyata.

Melalui aplikasi pengolahan KPI karyawan, analis mampu membuat KPI melalui backend website dengan mudah dan programmer dapat mencari KPI melalui mobile apps dan memilih KPI yang sesuai secara cepat. Dan perusahaan dapat menilai kinerja karyawannya berdasarkan akumulasi KPI yang terdapat di dalam sistem usulan ini. Sistem usulan ini juga memiliki fasilitas pencarian data, sehingga memudahkan pengguna dalam melakukan pekerjaannya.

Penulis berpendapat bahwa aplikasi mobile apps untuk pengolahan KPI karyawan ini adalah solusi dari masalah yang dialami oleh PT. Solutech Global dalam mengolah data KPI karyawan.

\section{REFERENSI}

Abdulloh, Rohi. 2018. Mudah Membuat Aplikasi Android dengan Ionic 3. Jakarta : PT. Elex Media Komputindo

A.C. Aditya. 2017. Teknik Perancangan Arsitektur Sistem Informasi. Yogyakarta : ANDI
Aminudin. 2014. Cara Efektif Belajar Framework Laravel. Yogyakarta : CV. Lokomedia

A.S, Rosa, M., Shalahuddin. 2013. Rekayasa Perangkat Lunak Terstruktur dan Berorientasi Objek. Bandung: Informatika

Gani, Lutfi. 2017. Menguasai AngularJS untuk Membuat Website Dinamis. Yogyakarta : Lokomedia

Indrajani. 2015. Database Design. Jakarta : PT. Elex Media Computindo

Kadir, Abdul. 2013. From Zero to A Pro Pemrograman Aplikasi Android. Yogyakarta : ANDI

Kadir, Abdul. 2017. Dasar Logika Pemrograman Komputer. Jakarta : PT. Elex Media Komputindo Raharjo, Budi. 2018. Belajar Otodidak Framework Codeigniter. Bandung : Informatika

Rubin, Kenneth S. 2013. "Essential Scrum”, Pearson Education Inc.

Sarosa, Samiaji. 2017. Metodologi Pengembangan Sistem Informasi. Jakarta : Indeks

Setiawan, Didik. 2017. Buku Sakti Pemrograman Web, HTML, CSS, PHP, MySQL \& Javascript. Yogyakarta : PT, Anak Hebat Indonesia

Subagja Anton. 2018. Membangun Aplikasi Web dengan Metode OOP. Jakarta : PT. Elex Media Komputindo

Sutabri, Tata. 2012. Analisis Sistem Informasi. Yogyakarta : Andi

Sutarman. 2012. Pengantar Teknologi Informasi. Jakarta : Bumi Aksara

Yasin, Verdi. 2012. Rekayasa Perangkat Lunak Berorientasi Objek.

Jakarta : Mitra Wacana Media 
Yudhanto, Yudo. dan Adi Prasetyo Helmi. 2018.

Panduan Mudah Belajar Framework Laravel.

Jakarta : PT. Elex Media Komputindo

Jurnal Teknologi Informatika \& Komputer| Volume 4 No. 1, Maret 2018

http://journal.thamrin.ac.id/index.php/jtik/article/view/306/263 